\title{
A rare case of plasmacytoid myoepithelioma of hard palate with cyto- histopathological correlation
}

\author{
Archana Shetty ${ }^{1}$, Vijaya C.,", Padma Priya Kasukurti ${ }^{3}$, Naveen ${ }^{4}$ \\ ${ }^{1,4}$ Associate Professor, ${ }^{2}$ Professor \& HOD, ${ }^{3}$ Assistant Professor, ${ }^{1,2,3}$ Dept. of Pathology, ${ }^{4}$ Dept. of ENT, Sapthagiri Institute of \\ Medical Sciences and Research Centre, Bangalore, Karnataka, India
}

*Corresponding Author:

Email: vijayachowdappa18@gmail.com

\begin{abstract}
Myoepitheliomas are rare benign salivary gland tumours almost exclusively composed of cells exhibiting myoepithelial differentiation. These tumours are likely to be underdiagnosed as they are rare and tend to be morphologically diverse Pleomorphic adenoma, basal cell adenoma and myoepithelioma usually lie on a continuum, with many overlapping features. In myoepithelioma the neoplastic myopeithelial cells can be spindly, plasmacytoid hyaline, epitheliod, clear or oncocytic, or combination of the above. Fine needle aspiration cytology (FNAC) in such cases may have limited diagnostic value, but nonetheless is important to rule out unsuspected malignancies. We present a case of a forty five year old female with a growth on the hard palate. The aspirates in our case very closely resembled cellular pleomorphic adenoma. However, detailed histopathological examination of the excised specimen along with relevant immunohistochemical markers proved it to be a case of plasmacytoid myoepithelioma.

We report this case to highlight the cytological features and differentials of this rare tumour, which can also be confirmed on histopathology.
\end{abstract}

Keywords: Hard palate, Pleomorphic adenoma, FNAC, Myoepithelioma, Plasmacytoid.

\section{Introduction}

Salivary gland tumours till date are a subject of great interest because of their histologic diversification. complex features exhibited by them have aroused speculations concerning their histogenesis and continues to hold the interest of clinicians and pathologists. myoepteliomas are rare salivary gland tumours which are exclusively composed of myoepithelial cells and often mimic the more commoner pleomorphic adenomas. Histologically the four variants are spindle cell, plasmacytoid, epithelioid and clear cell. ${ }^{1}$ Although myoepithelioma was documented in literature as a variant of pleomorphic adenoma, with exclusive myoepithelial differentiation studies have documented it as a standalone entity. ${ }^{2} \mathrm{We}$ report a case of a plasmacytoid myopethelioma of the hard plate in a middle aged female. The cytological features, histomorphological features and immunohistochemical features of the same are also discussed.

\section{Case Report}

A female, aged forty five years presented to the ENT outpatient department of our hospital, with complaint of a growth over the hard palate, noticed by the patient since six months. The swelling was now gradually increasing in size and was painful since a week. On examination, a midline swelling was noted on the hard palate measuring $1.5 \times 1 \mathrm{cms}$, with overlying mucosa being intact. Fine Needle Aspiration cytology was done. Aspirate was haemorrhagic. Smears were highly cellular showing epithelial cells in papillary configuration, sheets, trabeculae and tubules. Many of the cells were plasmacytoid with abundant eosinophilic cytoplasm and eccentric nucleus.

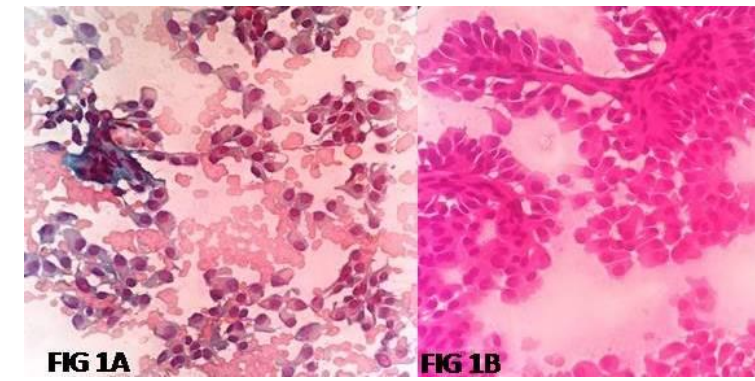

Fig. 1a: Aspirate smears showing sheets of plasmacytoid cells having eccentric nucleus. Pap $X$ 100; 1b: Morphology of plasmacytoid cells having eccentric bland nucleus and abundant cytoplasm $H$ \& E X100

Also seen were singly scattered plasmacytoid cells. Some of the epithelial cells showed intranuclear inclusions. Background was haemorrhagic. The differentials considered were - Cellular pleomorphic adenoma and myoepithelioma. An excisional biopsy of the swelling was done.The excised swelling measured $1.5 \times 1 \mathrm{cms}$ across and was pearly white to grey brown on cutting open. Histopathological examination of the excised specimen showed a thinly encapsulated tumour composed of trabeculae, tubules, papillae and solid sheets of cells. The cells were plasmacytoid with eccentrically located nucleus, abundant eosinophilic cytoplasm, few showing prominent nucleoli. 


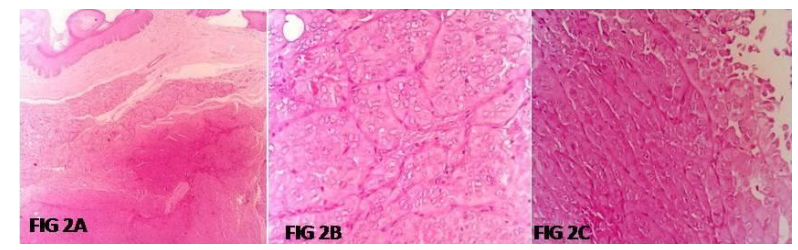

Fig 2a: A well encapsulated neoplasm with overlying lining of stratified squamous (hard palate)

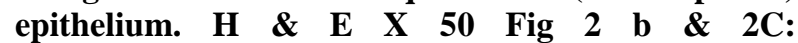
Microhotograph showing tubules surrounded by hyaline material and cross sections of papillae of plasmacytoid cells H \& E X 400

At places the tubules were lined by thin eosinophilic basement membrane material. An occasional foci of duct formation was seen. Stroma was minimal. Adjacent compressed salivary gland tissue seen was unremarkable. For academic completion purpose Immunohistochemistry was done. S100 and calponin was strongly positive. SMA showed focal positivity and $\mathrm{Ki}-67$ index was less than $1 \%$.

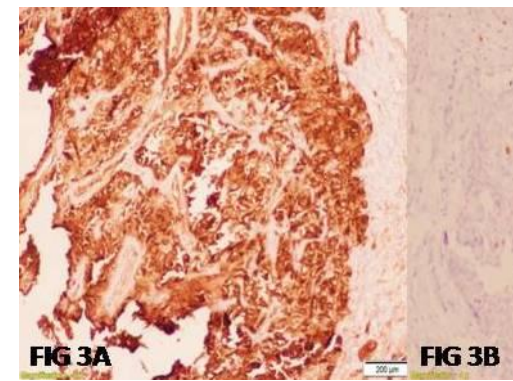

Fig 3a \& 3b: IHC showing diffuse strong positivity for calponin (3a) and a Ki-67 index of less than 1\%

A final diagnosis of plasmacytoid myoepithelioma of the hard palate was conferred upon. The patient came for a routine follow up after two months and was symptomless.

\section{Discussion}

The entity of 'myoepithelioma' was first coined by Scheldon in 1943. Although considered to be at the extreme form of cellular pleomorphic adenoma, the WHO classified it as a separate entity in 1991 .Myoepitheliomas account for $<1.5 \%$ of all salivary gland tumors. The most common location of myoepithelioma in the head and neck region are parotid gland $(40 \%)$ and the palate $(2 \%){ }^{4}$

The utility of FNAC in the diagnosis of salivary gland tumour is questionable, however, the cytological diagnoses can help the operating surgeon plan the best possible surgery. Not many studies have thrown light on the cytological features of myoepitheliomas. Aspirtaes of myoepithelioma are often cellular. Myoepithelial rich tumours like cellular pleomorphic adenoma, myoepithelial carcinoma must also be considered. Morphologically myoepithelial cells may be hyaline type, plasmacytoid, spindle cell and clear cell. In our case also, the aspirates were cellular showing predominantly myoepithelial cells. However, the myoepithelial cell in our case were plasmacytoid. The differentials of plamacytoma, lymphoma, malignant melanoma also need to be considered. Absence of Russel bodies and perinucelar hoff rules out plasmacytoma, absence of melanin pigment rules out melanoma. ${ }^{5}$ In pleomorphic adenoma the chondromyxoid matrix is a diagnostic feature, which can however be deceptively absent in cellular pleomorphic adenomas. There was no mitotic activity or necrosis ruling out the possibility of any carcinoma or lymphoma. Features like intranuclear inclusions and nuclear grooves as seen in our case are known to occur in myopitheliomas. ${ }^{6}$ Adenoid cystic carcinoma shows characteristic hyaline globules with surrounding small blue cells with hyperchromatic nuclei.

On computed tomography, palatal myoepitheliomas present as well defined lesions with smooth contor, with slight erosion of the maxillary bones. Erosion of the bones is not an evidence of malignancy as it can also be seen in other benign salivary gland tumours like pleomorphic adenomas. ${ }^{7}$

Histologically, the morphological variants (as mentioned above) in myopeithelioma do not have any prognostic significance, but do alter the considerations for differential diagnosis. The same features as seen on cytology can be seen on histopathology, helping in differentiation of this tumour from other tumours. The closest tumour from which myoepithleioma needs to be differentiated is pleomorphic adenoma with predominant myoepithelial component. It has been documented that salivary gland tumours containing less than $5 \%$ of ductal and acinar components must be named myoepithelioma. ${ }^{1}$ In our case only an occasional ductal component was seen at one edge of the tumour, the rest of it being sheets of plamscytoid cells. Also intense stromal hyalinization was noted around the plasmacytoid cell groups, this however was not associated with any chondroid or osteoid tissue ruling out even the remote possibility of pleomorphic adenoma. Similar case has been reported in literature till date. ${ }^{4,8}$ Oncocytoma was also considered to be a possibility, but was ruled out as the oncocytes have a granular cytoplasm in comparison to the hyaline agranular cytoplasm of the myoepithelial cells. ${ }^{9}$ The other close differentials considered were plasmacytoma, lymphoma and rhabdoid tumours, none of the features of which were seen on histopathology..$^{5}$ The benign nature of the tumour was further confirmed by the absence of mitoses, necrosis and cellular pleomorphism.

Akin to their varying histologic patterns, myoepitheliomas also exhibit disparities in their immunoprofile, hence relying on a single marker is usually not advised..$^{10}$ This may be one of the reasons why tumour cells vary in the spectrum of markers expressed. Studies till date have shown positivity for S- 
100, GFAP and Vimentin., ${ }^{4,9}$ The debate till date is on the expression of SMA by the plasmacytoid myoepithelial cells. Studied have documented both positive $^{5,9}$ and negative ${ }^{11}$ results for SMA. This may be attributed to the Tumour myoepithelial cells exhibiting different stages of differentiation leading to mixed results for SMA. ${ }^{4}$ However, larger studies on the utility of this marker in a panel to diagnose plasmacytoid myoepithelioma needs to be carried out.

Although the treatment of myoepithelioma is limited to surgery with a rim of uninvolved margin, regular follow up is recommended as the tumour is known for recurrence ${ }^{[9,10]}$ The lady in our case was followed up without any signs of recurrence for a period of six months

\section{Conclusion}

Plasmacytoid myoepithelioma is a rare, unique tumour of its kind, which is now categorized as a separate entity. The histogenesis and differentiation of this tumour till date remains controversial, as studies are not many regarding the immunohistochemical aspect of this tumour. Nevertheless, cytological and histomorphical features, if not overlooked can help in the diagnosis of this form of myorpithelioma for which surgical excision is suffice.

Acknowledgements: We thank the staff of Department of ENT of our hospital for providing this case for our study.

Conflict of Interest: The authors declare that they have no conflict of interest of any sort pertaining to the study

\section{Funding: None}

\section{References}

1. Sethi D, Ahluvalia C, Khatri A, Khetarpal S. Palatal plasmacytoid myoepithelioma. Advanced Biomedical Research. 2012;1:78.

2. Politi M, Toro C, Zerman N, Mariuzzi L, Robiony M. Myoepithelioma of the parotid gland: Case report and review of literature. Oral Oncol. 2005;41:104-8.

3. Ellis G, Anclair P. Benign epithelial neoplasms. Tumors of Salivary Glands. AFIP. 2002:57-68.

4. Santos EP, Cavalcante DR, Melo AU, Pereira JC, Gomes MZ, Albuquerque RL. Plasmacytoid myoepithelioma of minor salivary glands: report of case with emphasis in the immunohistochemical findings. Head \& Face Medicine. 2011;7:24.

5. Kulkarni PR, Javalgi AP, Pottipati B, Shajahan F. Plasmacytoid Myoepithelioma of the Hard Palate in a Child - A Rare Case Report. Journal of Clinical and Diagnostic Research : JCDR. 2015;9(10):ED01-ED02. doi:10.7860/JCDR/2015/13800.6583

6. Cuadra Zelaya $F^{1}$, Quezada Rivera D, Tapia Vazquez JL, Paez Valencia C, Gaitán Cepeda LA.

Plasmacytoid myoepithelioma ofthe palate. Report of one case and review of the literature Med Oral Patol Oral Cir Bucal. 2007 Dec 1;12(8):E552-5.

7. Mubeen K, Vijayalakshmi KR, Pati AR, Girish B, Giraddi GB, Singh C: Beningn pleomorphic adenoma of minor salivary gland of palate. J Dent Oral Hygiene 2011, 3:82-88.

8. Sugiura R, Kuyama K, Utsunomiva T, Morikawa M, Fukumoto M, Yamamoto H: Myoepithelioma arising from the buccal gland:histopathological and immunohistochemical studies. J Oral Sci 2000,42:39-42.

9. Gore CR, Panicker N, Chandanwale S, Singh BK. Myoepithelioma of minor salivary glands - A diagnostic challenge: Report of three cases with varied histomorphology. Journal of Oral and Maxillofacial Pathology : JOMFP. 2013;17(2):257-260. doi:10.4103/0973-029X.119748

10. Ponce Bravo $S^{1}$, Ledesma Montes C, López Becerril U, Morales Sánchez I Myoepithelial cells are the main component in pleomorphic adenomas? Med Oral Patol Oral Cir Bucal. 2007 Mar 1;12(2):E110-5

11. Rani P, Kaur R, Malhotra D, Dass PK, Sachdeva S, Kapoor R. Plasmacytoid Myoepithelioma of The Palate In An Adolescent - A Case Report And Review of Literature. Indian Journal of Dental Sciences. 2014;6(2):55-57. 